\title{
Online Book Acquisition Practices: A Study
}

Manimalar. R, Krithika. M, Fabian Andrew James

Department of Management

Vels University

Chennai, India

ABSTRACT: Purpose: In the last few years, Internet penetrates the life of the people and many decisions are made based on the web information and the decision process is based on the availability of many options. One such major activity where people use the web is for the selection of books which becomes an online process. There are several online platforms available to the end users to make purchase decision. In this work we selected a few online book selection platforms and made an extensive analysis of the data extracted from these online platforms.

Design/Methodology: For the data collection we have used the questionnaire using confirmatory factor analysis and Structural equation model. These two systems were used to measure the relationship between the variables. We have employed a few variables such as how the measure is valid, how it is flexible and what is the ease of access. The questionnaire is used to draw data from a group of selected students who used online book selection tools.

Findings: The findings reveal that internet technology has invaded the minds of the young people towards online purchase of books, course materials and chat with professional experts. Reliability, Openness, Feasibility are the most influential variables that trigger the young minds to shop books online. The SEM model was found to acceptable and there was a good fit among the variables.

Practical Implications: The paper analyses the most predominant factor that influences the online shopping behavior of young people. To be successful, the online book sellers should be aware about the variables that capture the young minds to go for online shopping. This study also enables the online retailers to know which factor increases the future online book purchases.

Originality/Value: The system we have used ensures novelty in our approaches. The model is able to extract the significant data and lead to the useful inferences. This work enables to draw the preferences and judge the variables that play role in selection of the books and finally it gives an understanding the satisfaction level and trust towards online book stores.

Keywords: Social Media, Internet Technology, Purchase Intention, Reliability, Feasibility, Openness

DOI: $10.6025 / \mathrm{pms} / 2019 / 8 / 2 / 39-47$

Received: 12 April 2019, Revised 3 July 2019, Accepted 9 July 2019

(C) 2019 DLINE. All Rights Reserved 


\section{Introduction}

In the last few years the Internet penetration among the society has been increasing rapidly. The Internet user popluation is set to record a high volume. The Indian Economy has boomed with the help of mobilization through internet connectivity this has increased the revenue to cross $\$ 500$ million with a CAGR of $103 \%$ over last 4 years. There are several online retail giants like Flipkart, Snap deal, Amazon, e-bay etc. which has a powerful impact in the virtual market on all sectors such as electronics, clothing, home appliances etc. These days there are more of its presence in capturing the young minds through the book business. Online shopping has made the purchase more flexible and easier especially for young students and gone are the days where we were unable to get the preferred books. These days we can choose a book of our liking in just minutes using internet technology.

This work is based on practival data extracted from questionnaires. The paper studies the various influential factors such as reliability, openness and feasibility towards the students to use the invading technology. This study comprises of young online shoppers who are educated, intensive, and expert users of the internet. They have strong positive perception towards online shopping with the increasing growth of the Internet. The online book stores have to adjust their respective strategies to maintain presence online and compete. Purchase intention is the exogenous variable and awareness, perception and accessibility are taken as the endogenous variables. The mediating variables taken for the study are reliability, openness and feasibility.

Internet has provided more options for college students across the nation in terms of buying books in recent years. The findings suggest that if there is a proper use of technology, access and awareness about the social media websites, it would lead to the students increase in purchase of books. There was a strong relationship between the exogenous and endogenous variables and the model was fit with the indices. Here we find that awareness, accessibility and perception which are the endogenous variables as a criteria for the students to go for online purchase. This study suggests the online book seller's measures that could increase the sales of their businesses.

\section{Review of Literature}

The users of internet are young, professional, and affluent with more income and they are well qualified (Palumbo and Herbig, 1998). Klassen et al. (2009) revealed a greater impact of offers towards online shopping purchase. This reveals that the preferences of online shoppers are the pointers of online shopping behavior. Gretzel (2006) indicates that usefulness, reliability and flexibility are the main criteria's for purchasing online products. Ease of use has been found to be the most important factor of technology to invade the minds of youth (Lee, Kozar \& Larson, 2003). Childers et al., (2001), and Heijden et al., (2001) also suggested that their attitude towards online shopping is affected by their perceived usefulness. Hence accessibility is considered to be one of the factor that affects purchase intention of young minds (Chen et al., 2002; Gefen \& Straub, 2000; Heijden et al., 2001; and Pavlou, 2001). Youngsters look for variety of choice, good price and delivery performance (Bhatnagar \& Ghose, 2004 ; Ahn et al. 2004, and Lee \& Joshi, (2007).

The usage of Internet and the amount of time spent on it has an impact on online shopping purchase. Students who use the internet for long hours are educated on the digital technologies and are equipped with skills, hence internet becomes feasible and accessible to them (Sisk, 2000; Hoffman and Novak, 1996; Liao and Cheung, 2001). The users who are using the internet extensively are considered to be active users (Emmanouilides and Hammond, 2000). Choosing the most prominent websites is the most difficult task for the students but this depends upon the feasibility and accessibility of the technology (Wan, Menon \& Ramaprasad, 2007). Kim et al., (2003) also explained the websites effectiveness so more effort is required to improve the quality of websites. He also insisted that the value of websites depend on 3 principles which are content and function adequacy, presentation quality, navigability. The author also highlighted that this performance of websites depends upon the reliability of websites and the time of response.

For Students the textbook is a very important factor for purchase of books as the awareness and search for books enables the students to select the books in their opinion. The e-business era has given the students as many options and a guide to purchase hence awareness on online shopping is playing a crucial role in the purchase of online products (Freeman, 1999; Hendel and Lizzeri, 1999; Li et al. 1999; Bhatnagar et al., 2000; Clay et al., 2001).

The students need to be aware about the cost of the purchase, the search time, waiting time and the risk involved before the 
purchase of the products. The students also look for price advantages from a variety of online stores before taking a decision on the purchase; hence the online shoppers make themselves aware about these factors before purchase. The online book stores hence have a tough time to give the services at a reasonable price and they need to be on par with the competitors. Price advantage has a greater significant on the student purchase behaviors, an awareness on this leads them to purchase (Cannon, 1999; Cader, 2001).

The phenomena of reliability are of high importance in online shopping consumer behaviour (Pavlou and Chai 2002). Consumers look for trust, security and risk for shopping online and lack of these factors are obstacles for shopping online. (Lee and Turban, 2001). The store ambience and store reputation influence the reliability of the online shoppers (Jarvenpaa, et at., 2000). In 1999 Ho and Wu illustrated that design of website and the reliability of the store are the most crucial factors that have most significant effect on online consumers.

As Bellman et al. (1999) mention, demographics are not so important in determining online purchasing potential. In online shopping the time constraints and accessibility to technology are more influential in their purchase potential. Customers who have a higher level of security and privacy concerns have a low percentage of using the online marketing websites (Kwak et al., 2002; Miyazaki and Fernandez, 2001). The students are found to be the most confident decision makers when it comes to online shopping, more demanding and have a great control over the purchase process from the initial stage till the completion stage (Rao et al., 1998).

Knowing the students intention of purchase is of utmost importance to know why the shop and not shop from the web marketers. This is the key to denote the essentials required to know that makes the students purchase online and the intriguing factors that push up the rate of student online customers. Identifying pre-purchase intentions of consumers is the key to understand why they ultimately do or do not shop from the Web market. One area of research under the online consumer behavior consists of studies that measure the variables that influence the intention of purchase. A list of determinants that the researchers have examined consists of: Vendor quality, Transaction security, Information and Service quality, the quality of the system, Security risk and privacy, shopping enjoyment and trust (Liao and Cheung, 2001; Saeed et al., 2003; Miyazaki and Fernandez, 2001; Chen and Dubinsky, 2003). The factors that have a positive and negative impact on customers to shop seem to be quite different or vary from offline environment.

An earlier study elaborated that there is a greater effectiveness when the online book stores target the colleges to make the students aware about the business, the feasibility of purchase and ease of use (Talaga and Tucci, 2001). The days are gone wherein internet text book retailers used to take orders and mail the products to the homes, in the new era the students are having awareness, perception and accessibility to text book which is a great advantage for the youths of today (Talaga and Tucci, 2001).

There are certain most important variables in the sales of college textbook as follows: (1) the availability of the books at the online store (2) the buyback policies and guarantees of the online book stores and (3) The price of textbooks offered at online bookstores (Chevalier and Goolsbee, 2003). Foucault (2002) describes a study in attempting to answer the question - why students buy textbooks online - by using online textbook purchasing as a model to outline predictors of online purchasing based on motivation theories drawn from traditional online consumer motivation research, social motivation theory, social influence theory and uses and gratifications theory. The study confirms a positive relationship between the uses of previous online purchases, positive social environments, professor support, knowledge of online retailers, as empirical variables, and the actual online textbook purchasing.

This objective of this study is focused on analyzing reliability, openness and feasibility as an influential and mediating factors between the dependent and independent variables.

\section{Objectives}

1) Influence of online websites on the mind of young people to purchase books.

2) To study the importance of accessibility, awareness and perception towards online purchase of books.

3) To study the influence of reliability, openness and feasibility on the purchase intention of students. 


\section{Research Methodology}

This research paper analyses the Internet usage towards the online Book purchase among the young students. Descriptive research design was used for this study. Simple Random Sampling has been derived from probability sampling method to select the students. Four Private Universities in Chennai were chosen to select the sample size. From the total Students population, 300 were distributed among the students of MBA department and 240 was the usable data that was collected through a Structured Questionnaire.

\section{Data Analysis}

Structural equation model is a multivariate analysis that is used to test the hypotheses (Hancock and Freeman 2001; Kline 2005). The SEM finds the series of dependence between variables and their relationships. The hypothesized model in figure is tested using Amos to determine the relationship between the endogenous variable and exogenous variables to find if there is a consistency of data. In order to measure the variables, the variables are classified as latent and observed variables. The exogenous variables used are Awareness, Perception and Accessibility and the endogenous variable is Purchase Intention. In SEM the latent variables were not observed directly. The measurements and their scores are termed as observed or manifest variables; they serve as an indicator for the constructs that they presume. In each latent variable there are more than four statements (observed variables) to measure the latent variable. The mediating variables such as Reliability, Openness and Feasibility are used to find the influence on the endogenous variable.

The Researcher explored the model fitness using the following indices: CMIN (or chi-squared), CMIN/df (CMIN divided by degrees of freedom), RMSEA (root mean square error of approximation), RFI (relative fit index), CFI (comparative fit index), NFI (normed fit index), and TLI (Tucker-Lewis index). In making fit determinations, the generally accepted thresholds (Hair et al.1998; Kline 2005), suggests that reasonably fit models are typically characterized by CMIN/df as high as 5, RMSEA values as high as 0.08 , and RFI, CFI, NFI, and TLI values of 0.90 or higher.

Person's correlation is used to find the relationship between the exogenous variables and is found to be significant. The same test is also used to find the relationship among the mediating variables and found to be correlated.

\section{Figures and Tables}

\subsection{Figures}

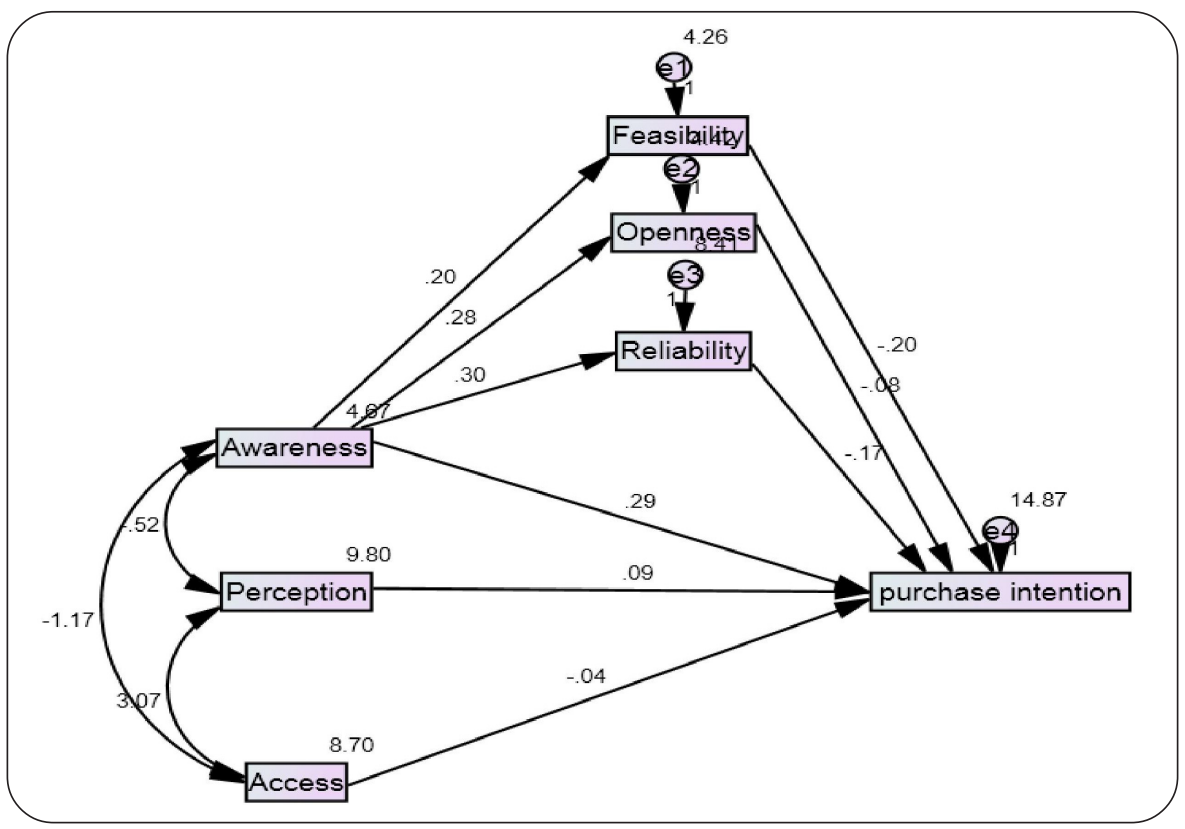

Figure 1. Source: Author’s SEM Model 


\subsection{Tables}

\begin{tabular}{|l|l|c|c|c|}
\hline \multicolumn{2}{|c|}{} & Awareness & Access & Perception \\
\hline \multirow{4}{*}{ Awareness } & Pearson Correlation & 1 & $-.183(* *)$ & -.077 \\
\cline { 2 - 5 } & Sig. (2-tailed) & & .004 & .236 \\
\cline { 2 - 5 } & $\mathrm{N}$ & 240 & 240 & 240 \\
\hline \multirow{4}{*}{ Access } & Pearson Correlation & $-.183(* *)$ & 1 & $.332(* *)$ \\
\cline { 2 - 5 } & Sig. (2-tailed) & .004 & & .000 \\
\cline { 2 - 5 } & N & 240 & 240 & 240 \\
\hline \multirow{7}{*}{ Perception } & Pearson Correlation & -.077 & $.332(* *)$ & 1 \\
\cline { 2 - 5 } & Sig. (2-tailed) & .236 & .000 & \\
\cline { 2 - 5 } & $\mathrm{N}$ & 240 & 240 & 240 \\
\hline
\end{tabular}

** Correlation is significant at the 0.01 level (2-tailed).

Table 1. Correlation between Independent variables

Pearson's correlation found a strong relationship between Awareness and Accessibility. The correlation between Awareness and Accessibility are significant at 1\% Level but there is no significance found between Awareness and Perception. The above table also shows a strong relationship between Accessibility and Perception at $1 \%$ Level wherein the $P$ Value is $<0.01$.

\begin{tabular}{|c|l|c|c|c|}
\hline \multicolumn{2}{|c|}{} & Reliability & Openness & Feasibility \\
\hline \multirow{7}{*}{ Reliability } & Pearson Correlation & 1 & $.164\left(^{*}\right)$ & .038 \\
\cline { 2 - 5 } & Sig. (2-tailed) & & .011 & .561 \\
\cline { 2 - 5 } & $\mathrm{N}$ & 240 & 240 & 240 \\
\hline \multirow{2}{*}{ Openness } & Pearson Correlation & $.164\left(^{*}\right)$ & 1 & $.324\left(^{* *}\right)$ \\
\cline { 2 - 5 } & Sig. (2-tailed) & .011 & & .000 \\
\cline { 2 - 5 } Feasibility & N & 240 & 240 & 240 \\
\cline { 2 - 5 } & Pearson Correlation & .038 & $.324(* *)$ & 1 \\
\cline { 2 - 5 } & Sig. (2-tailed) & .561 & .000 & \\
\cline { 2 - 5 } & N & 240 & 240 & 240 \\
\hline
\end{tabular}

* Correlation is significant at the 0.05 level (2-tailed).

Table 2. Correlation between Mediating variables

The above table given shows a strong relationship between the mediating variable Reliability and Openness as well as a strong correlation between Openness and Feasibility. The $p$ value found between Reliability and Openness is 0.011 which is $<0.05$ hence significant at $5 \%$ level, where as the $p$ value found between Openness and Feasibility is 0.000 which is $<0.01$ and significant at $1 \%$ Level. There is no correlation found between Reliability and Feasibility. 


\begin{tabular}{|l|l|c|c|c|c|c|c|}
\hline \multicolumn{2}{|c|}{} & \multicolumn{5}{c|}{ HOURS USE } & Total \\
\hline \multicolumn{2}{|c|}{} & LESSTHAN 1 HOUR & $\mathbf{1}$ - 2 HOURS & $\mathbf{2}$ - 3 HOURS & $\mathbf{3}$ - 4 HOURS & $\mathbf{5}$ Hours & \\
\hline Gender & FEMALE & 16 & 59 & 34 & 4 & 24 & 137 \\
\hline & MALE & 16 & 45 & 18 & 12 & 12 & 103 \\
\hline Total & 32 & 104 & 52 & 16 & 36 & 240 \\
\hline
\end{tabular}

Table 3. Gender and internet hours usage - Cross Tabulation

Cross Tabulation test is conducted to find the difference between male and female on the usage of internet based on the hours used. The above test shows that out of the 240 samples 137 females and 103 males use the internet. Here the females use the internet extensively for 1-2 hours and 2-3 hours where as the males use the internet extensively for 3-4 hours and again female use more of internet for 5 hours. Hence females use the internet for more hours than their male counterparts.

\begin{tabular}{|l|c|c|c|c|c|c|}
\hline & \multicolumn{5}{|c|}{ LONGSHOPPING } & Total \\
\hline & LESS THAN 6 Mt & 6 MONTHS - 1 YEAR & 1 - 2 YEAR & 2- 3 YEARS & MORE THAN 4 Yrs & \\
\hline gender FEMALE & 56 & 40 & 19 & 14 & 8 & 137 \\
\hline & 24 & 44 & 25 & 6 & 4 & 103 \\
\hline Total & 80 & 84 & 44 & 20 & 12 & 240 \\
\hline
\end{tabular}

Table 4. Gender and Internet Browsing - Cross Tabulation

The same test is also run to find the difference between male and female in terms of Internet browsing for long shopping. The test in table 6.2.4 clearly shows that 56 females have been using the internet less than 6 months for shopping where as only 24 males have been using it for less than 6 months. 40 females and 44 males have been using the internet from 6 months to 1 year for shopping, 19 females and 25 males use the internet for shopping from $1-2$ years, 14 females and 6 males have been using it for 2-3 years and finally 8 females and 4 males had used the internet for shopping for more than 4 years. Here we find females usage of internet more than males for shopping online.

\begin{tabular}{|c|l|c|c|c|c|}
\hline \multicolumn{2}{|c|}{} & \multicolumn{3}{c|}{ LEVEL OF ONLINE } & Total \\
\hline \multicolumn{2}{|c|}{} & BEGINNER & INTERMEDIATE & EXPERT & BEGINNER \\
\hline \multirow{2}{*}{ gender } & FEMALE & 89 & 36 & 12 & 137 \\
\hline \multirow{2}{*}{ Total } & MALE & 63 & 32 & 8 & 103 \\
\hline
\end{tabular}

Table 5. Gender and level of online - Cross Tabulation

Cross tabulation is also run to find whether the respondents are beginner users or intermediate users or expert users when it comes to usage of internet. The above table indicates that 89 females and 63 males are beginner users of internet, 36 females and 32 males are intermediate users and 12 females and 8 males are expert users of internet. 


\begin{tabular}{|l|l|l|l|l|l|}
\hline Model & NPAR & CMIN $(\mathbf{x ~ s q )}$ & Df & P & x sq/df \\
\hline Default Model & 20 & 2.107 & 1 & 0.147 & 2.107 \\
\hline Saturated Model & 21 & .000 & 0 & & \\
\hline Independence Model & 6 & 720.251 & 15 & .000 & 48.016 \\
\hline
\end{tabular}

Table 6. SEM Model fit Summary

\begin{tabular}{|l|c|l|}
\hline Fit Statistic & Recommended & Obtained \\
\hline $\mathrm{x} \mathrm{sq}$ & - & 2.107 \\
\hline $\mathrm{df}$ & - & 1 \\
\hline $\mathrm{x} \mathrm{sq}$ Significance & $\mathrm{P}<=0.05$ & 0.001 \\
\hline $\mathrm{x} \mathrm{sq} / \mathrm{df}$ & $<5.0$ & 2.107 \\
\hline GFI & $>0.90$ & 0.96 \\
\hline AGFI & $>0.90$ & 0.92 \\
\hline NFI & $>0.90$ & 0.96 \\
\hline RFI & $>0.90$ & 0.91 \\
\hline CFI & $>0.90$ & 0.94 \\
\hline TLI & $>0.90$ & 0.92 \\
\hline RMSEA & $<0.08$ & 0.12 \\
\hline RMR & $<0.10$ & 0.10 \\
\hline
\end{tabular}

Table 7. SEM Model fit Indices

\section{Findings}

The results shown Table 6.2.6 gives an overview on the model fit. In SEM a small chi-square value supports the model that is being tested. In the above model we see that the $x s q$ value is 2.107 which are small when we compare with the Independence model (48.016). This reveals that the $x s q$ value is of a good fit. Here the $x s q$ value is divided by the degrees of freedom to give 2.107. According to experts, the metric value should not exceed 5 for models that have a good fit. Here, if we look at the table 6.2.6 we see that the $x s q / d f$ is 2.107 which is an acceptable model fit.

The table 6.2.7 shows recommended values that suffice a good model fit and the obtained value for this study. The other different model fit values that are used to verify if there is a goodness of fit and whether it is acceptable is mentioned below.

From the Table 6.2.7 statistics we should take note that $x s q$ for a just identified model usually equals zero and has no degrees of freedom. It also should be noted that if $x s q=0$, the model is perfectly fit. The $x s q$ here is 2.107 which is a good model fit.

$G F I=1.0$ indicates that the model is fit perfectly; the $G F I$ is greater than 0.90 indicating a good fit. In the above table the Goodness fit index got is $>0.90$ indicating that the model is a good fit model. The AGFI in the table is 0.92 which is also greater than the recommended value of 0.90 showing a good fit. The Normed fit index (NFI), Relative fit index (RFI), Comparative fit index 
(CFI) and the Tucker Lewis Index (TLI) are $0.99,0.95,0.99$ and 0.97 respectively showing values that are greater than 0.90 indicating that the model is fitting well.

The RMSEA value is 0.07 which is also within the recommended value of 0.08 and RMR is also $=$ to the limit showing an overall acceptable fit.

\section{Conclusion and Suggestions}

Nowadays Online shopping has become a common activity and more number of students use the internet technology to acquire knowledge on their subjects. Many tools such as Computer, Smart phones, Tablets are available to use these technologies with the help of WIFI function. Today many colleges have provided the WIFI service for students to browse internet. As there is a rise in number of people purchasing online, it is important to determine the attitude towards online purchasing behavior. This paper examined the influence of mediating factors towards the purchase of books through online. Students not only buy books but also clothing and its accessories, electronic items, they do travel booking. Secured transaction, Delivery Time, Competitive Price tag, Access to Content, Broader selections of books are most important factors that students consider while purchasing books online. This new developing concept of retailing has captured the interest of retailers and businesses, financial institutions, telecommunication service providers, government officials and even student communities because by virtue of its unique characteristics. Online purchase has the potential of becoming a dominant alternative shopping channel in the near future that cannot be easily challenged by the conventional retailing method. Online purchase is supplementary or complementary to existing business as an additional marketing, promotion and fulfillment channel. Furthermore it provides insights into the students' online purchase behavior, which may be important for online retailers in order to provide better services and enter broader into online selling market. Future research can be done by extending this study into different respondents such as shoppers with different socio-economic status and study can be done on different items such as Clothing, electronic items, home appliances etc. Also research can be done on Shoppers emotions after buying the product.

\section{References}

[1] Alreck, P., Settle, R. (2002). The hurried consumer: time-saving perceptions of internet and catalogue shopping. Journal of Database Marketing, 10 (1) 25-35.

[2] Arnold, S. J., Handelman, J., Tiger, D. J. (1996). Organizational legitimacy and retail store patronage. Journal of Business Research. 35, 229-239.

[3] Bellman, S., Lohse, G., Johnson, E. (1999). Predictors of online shopping behavior. Communications of the ACM. 42 (12) 3238.

[4] Bhatnagar, A., Misra, S., Rao, H. R. (2000). Online risk, convenience and internet shopping behavior. Communications of the ACM. 42(11) 98-105.

[5] Borchers, A. (2001). Trust in Internet shopping: A test of a measurement instrument. In: Proceedings of the $7^{\text {th }}$ Americas Conference on Information Systems, 11, 799-803.

[6] Burke, R. R. (2002). Technology and the customer interface: What consumer want in the physical and virtual store. Journal of the Academy of Marketing Science, 30 (4). 13, 441-432.

[7] Calder, B. J., Philips, L. W., Tybout, A. (1981). Designing research for application. Journal of Consumer Research, 8 (September), 197-207.

[8] Cho, Y., Im, I., Hiltz, R., Fjermestad, J. (2001). Causes and outcomes of online customer complaining behavior: implications for customer relationship management (CRM). In: Proceedings of the 7th Americas Conference on Information Systems, 6, 900-907.

[9] Citrin, A. V., Stem Jr., D. E., Spangenberg, E. R., Clark, M. J. (2003). Consumer Need for Tactile Input: An Internet Retailing Challenge. Journal of Business research, 56 (11) 915-923.

[10] Grandon, E. E., Ranganathan, C. (2001). The impact of content and design of web sites on online sales. In: Proceedings of the 7th Americas Conference on Information Systems, 5, 920-926.

[11] Ho, C., Wu, W. (1999). Antecedents of consumer satisfaction on the internet: an empirical study of online shopping. In: Proceedings of the 32nd Hawaii International Conference on System Sciences, 8, 38-45. 
[12] Jarvenpaa, S. L., Todd, P. A. Consumer reactions to electronic shopping on the World Wide Web, International Journal of Electronic Commerce, 1 (2) 59-88, 1996-1997.

[13] Kim, E. B., Eom, S. B., Yoo, S. (2001). Effective user interface design for online stores in the Asia Pacific region: A survey study. In: Proceedings of the 7th Americas Conference on Information Systems, 4, 867-872.

[14] Wu, S. L. (2003). The relationship between consumer characteristics and attitude toward online shopping. Marketing Intelligence and Planning, 21, 37-44.

[15] http://www.slideshare.net/dimputripathi/mr-reporthttp://articles.timesofindia.indiatimes.com/2013-04-01/pune/ 38188705_1_old-books-college-students-site 